\title{
TESTING PLASTIC FLOORING MATERIALS
}

$\mathrm{T}$ HE testing and examination of plastic flooring materials such as asphalt, vinyl-asbestos, vinyl and linoleum, more particularly performance behaviour, continue to present certain practical difficulties. An objective attempt to clarify the position as it now is, and to prepare the way for further research on test procedures at present considered inconclusive, was recently made by M. J. Nix, chief research officer of the National Building Research Institute, South African Council for Scientific and Industrial Research, Pretoria*.

The scope of this paper is comprehensive, embracing as it does the four materials quoted, each in respect of the examination of the following properties: flexibility; brittleness; curl; dimensional stability; resistance to abrasion, indentation, tear, scratching, detergents and cleaning solution, to fire and to cigarette burns; dis. coloration when exposed to solar radiation and to ultraviolet light radiation; acoustical properties; and slipperiness. The Tinius Olsen instrument (A.S.T.M. D747-50) was used to determine stiffness in flexure (lb./in. ${ }^{2}$, and despite their heterogeneous nature, a clear distinction between the different materials was obtained. Brittleness was assessed by the falling ball impact test (interim Federal specification $L-T-75 \mathrm{l}$ ), only one sample of asphalt failing, from which is concluded that this standard test is only significant in cases of extreme brittleness. Tests for curl were made in accordance with the same specification; in some samples 'natural curl', regarded as an inherent defect, made testing of this property impossible. In the tests for dimensional stability (again in accord with $L-T-751$ ) it was shown that vinyl-asbestos tiles recorded greatest shrinkage; the largest average shrinkage is of the order of $0 \cdot 1$ per cent, in practice negligible. Vinyl flooring showed either shrinkage or expansion; it is suggested that a more suitable routine test should be used to detect excessive dimensional changes of more than 1 per cent.

Abrasion resistance was tested on a 'Taber' abrader (A.S.T.M. D1242-56) and also on a newly designed abrasion tester, of which details are given, developed by

* Rilem Bulletin. Tome special. Symposium of Liège, 1964. Ref. RD 70. (Pretoria: Council for Seientific and Industrial Research, 1964.) the National Building Research Institute; the results indicate ". . . that the N.B.R.I. abrader shows values that are more comparable with actual wear than those obtained on the Taber abrader". Since the introduction of stiletto heel tips fitted with protruding nail-heads, resistance to indentation of these materials has become an increasingly important property; here again the test procedure accorded with the Federal specification $L-T-751$, but although vinyl appears to resist indentations better than the others, it is considered that conditions of temperature and time for this test method require further critical investigation. In the resistance to tear (A.S.T.M. D1004-49T), vinyl proved three times as good as other samples, but it is thought that the difference is not of much practical importance, 300-500 lb./in. compared with a minimum tear strength of $100 \mathrm{lb}$./in., desirable from the point of view of handling a flooring material. In the scratch test $(L-T-751)$ asphalt tiles seem slightly less resistant than linoleum and vinyl-asbestos, while vinyl sheeting varied from very good to poor; some doubt on the efficiency of the scratch tester involved is raised.

Linoleum emerges worst as regards chemical attack. Resistance to fire, cigarette burns and extinguishing cigarettes, by the methods detailed, are somewhat inconclusive, but vinyl sheet showed the best rating on resistance to cigarette burns, linoleum the highest rating on "extinguishing cigarettes". The tests of discoloration when exposed to solar and ultra-violet radiations gave interesting but variable results, some of which are illustrated in two coloured plates; brief details are given. Methods of assessing acoustical properties and slipperiness are discussed.

The conclusions reached are that the following aspects of all this work need further investigation: influence of accelerated ageing on flexibility and abrasion resistance; influence of temperature on flexibility and indentation resistance; influence of chemical agents in relation to indentation testing; and the influence of polish and wax on floor slipperiness in relation to various soling materials. Altogether this paper is a valuable and most welcome contribution to problems of performance testing of these flooring materials.

\section{'AEROLITE' AND ‘ARALDITE' BONDING MEDIA}

\begin{abstract}
' $\mathbf{E}$ ROLITE' is a synthetic glue manufactured by Ciba (A.R.L.), Ltd., extensively used for bonding timber in building and other constructional work; examples are laminated wood members in building design, glued formwork for concrete emplacement, both recently noted (Nature, 204, 129, 1139; 1964). 'The 'Araldite' range of epoxy resins, manufactured by the same firm, constitute the basis of formulations used inter alia for bonding metal to wood, as embedding media in biological research, for example, examination of animal and plant tissues in thin sections cut by microtome.
\end{abstract}

A specialized use of 'Aerolite' is in construction of timber building elements and particularly interior woodwork for churches and similar edifices. In this connexion a recent publication, entitled Church Furniture Bonded With Aerolite*, is of some arboreal interest quite

* Ciba (A.R.L.), Ltd., Technical Note No. 262, October 1964. Pp. 8 (Duxford: Ciba (A.R.L.), Ltd., 1964.) apart from the efficacy of the gluing medium concerned. It is pointed out that use of English oak in church structures and interior timber equipment is traditional; that the searcity of really big oak trees in Britain to meet what were formerly considered essential dimensional requirements "in one piece" is now vory roal. "Oak members in the lantern of Ely Cathedral, built in the fourteenth century, are $64 \mathrm{ft}$. long and $3 \mathrm{ft}$. square, and it is said that the whole country was searched for trees big enough to supply these timbers. To-day, with many of the old forests gone, one would seek in vain for trees of this size and, even oxtending one's search much farthor afield, one might well continue to be unsuccessful." To-day, large wooden structural members can be built up from relatively small pieces of oak or other timber to make any required unit size, with the aid of modern synthetic resin glue such as 'Aerolito'. The art of joinery as practised now by experts conceals glue-lines and, 
although the particular moulded member is composite, the resulting effect is that of solid timber, incidentally possessing extremely durable properties; since the structure of the unit is composite, inherent stresses natural to solid timber are reduced; there is little or no prospect of cracking or splitting. This publication describes and illustrates this type of work as carried out by Ebdons (Beddington), Ltd., of Croydon, who have had long experience of building church furniture and selecting the best possible timber for conditioning by kiln drying for this special purpose. Examples of this skilled workmanship in glued timber structures as shown includo churches and chapels in Belham, Bromley, Walworth, Sutton and Cheam, Harting near Petersfield, and Eridge Castlo, Sussex.

The use of 'Araldite' in bonding metal to woodwork is exemplified in the case of a processional cross (illustrated) which ". . . has the shaft reinforced with a steel rod bonded with Araldite epoxy resin. The same adhesive is used for the bonding of metal fittings on communion rails, chairs, lecterns, etc.". In a later issue of Ciba Technical Notes $\dagger$, an account is given of the use of "Araldite in Electron Microscopy". In this field it is used as an embedding medium of great stability. In the examination of animal and plant tissues with an ordinary laboratory microscope, paraffin wax is the standard embedding compound from which the requisite thin sections are cut by microtome; but with the electron microscope, exceptionally thin sections are required, and certain synthetic resins have been investigated. According to a report by Miss Audrey M. Glauert, Strangeways Research Laboratory, Cambridge, on which these technical notes are based, ". ... formulations based on Araldite epoxy resins have been found to be eminently successful, and such formulations have been adopted in research laboratories throughout the world".

H. B. MHLNER

† No. 263. Pp. 8. (Duxford: Ciba (A.R.L.), Ltd., 1964.)

\section{PHOTO-NEURO-ENDOCRINE EFFECTS IN CIRCADIAN SYSTEMS}

$I_{\mathrm{r}}^{\mathrm{T}}$ is well established that the exact timing of 24-h rhythms is dependent on environmental influences, and that when all such influences are removed, although the rhythm may persist it is no longer synchronous with solar time but becomes free-running with a periodicity of anything between 20 and $28 \mathrm{~h}$. The importance of the influence of daily changes of light and darkness on many daily and seasonal rhythms in both sickness and health has been recognized, if only dimly, since the times of Hippocrates. A great deal is now known about this influence of light on physiological processes and of the neuro-endocrine pathways involved. The Proceedings of a symposium on "Photo-Neuro-Endocrine Effects in Circadian Systems, with Particular Reference to the Eye"* comprise a comprehensive survey, by the workers eoncerned, of the more recent additions to this knowledge. While there is some evidence that light waves, when they can penetrate sufficiently deeply, may act directly on hypothalamic structures in both avian and mammalian species, the more general influence of light on the sympathetic system is through a specific nervous pathway from the eye to the hypothalamus. Through the hypothalamic-hypophyseal connexions light can influence the endocrine discharges from the pituitary lobes. It is not surprising, then, to learn that the intensity and duration of light exposure can influence a great number of sympathetically and hormonally controlled physiological functions, particularly those of body temperature, reproduction and metabolism.

Halberg's term 'circadian', to describe the de-synchronized or free-running endogenous rhythmicity of only approximately $24 \mathrm{~h}$, is now generally accepted, at least in North America, and is clearly defined in the course of Dr. Hague's opening remarks. In some of the subsequent papers, however, no sharp distinction is made between the terms 'diurnal' (when used to describe a rhythm or activity over a period of $24 \mathrm{~h}$ ) and 'circadian'. In a paper by Halberg and others, the term 'circadian' is extended to include "the special case of an exact 24-h period". This is consistent with Halberg's use, in another paper, of the word 'diurnal' in the more fundamental sonse to describe an activity in relation to day-time, as opposed to 'nocturnal' and 'night-time'. Whether the term 'diurnal activity' used elsewhere in the volume describes an activity restricted to the day-time, or

* Annals of the New York Academy of Sciences. 117, Article 1: PhatoNeuro-Endocrine Effects in Circadian Systems, with Particular Reference to the Eye. By E. B. Hague and 64 other during a 24-h period, is not at all clear. This is most confusing. In view of the stricture made on the use of the word 'circadian' by Williams in $1963^{1}$, it would be well if agreement could be reached on the use of these terms. We now have three distinct words and three distinct, or distinguishable, meanings which could be used as follows: (I) diurnal, that is, pertaining to the day-time, the complement to 'nocturnal'; (2) nychthemeral (or nycthemeral, as used by French-speaking biologists), that is, relating to solar time, a period of $24 \mathrm{~h}$, consisting of a night and a day (Shorter Oxford English Dictionary); (3) circadian, that is, the description of an approximately 24-h free-running endogenous rhythmicity. Perhaps the ambiguity of 'diurnal' is too deeply rooted for any plea for its eradication to be heard, but if the new term 'circadian' is to be wholly acceptable, its meaning must be made perfectly elear.

As is often the case with Proceedings of symposia by students of many disciplines and from many countries, this volume is not uniformly easy to assimilate, but it quickly arouses and sustains the interest of the reader. Strictly verbatim reporting of discussions can be irritating, especially when accompanying slides are not reproduced as figures. There is clear evidence, in at least one paper, of considerable alteration to the text subsequent to its original presentation. This would seem to destroy the whole premise for verbatim reporting elsewhere, and careful editing would not have obscured the valuable points which were sometimes raised in discussion. However, the symposium was well conceived, and was well balanced between the fundamental biological significance of the influence of light on physiological processes, and its considerable medical importance. While the subjectmatter of some of the papers is not strictly within the terms of reference given in the title of the symposium, they afford a broader understanding of other inter-related factors which should not be ignored in a study of specific physiological processes. Papers on autonomic conditioning and the hypothalamic-hypophyseal neural influence in periodic diseases, for example, give depth to the more general consideration of the nature of biological rhythms, in both normal and abnormal conditions, while the two papers on control theory in relation to biological systems have even wider application and interest. This volume will be a valuable source of information for some long time to come.

JOHN BLIGH

Press, London, 1963). 